\title{
NOÇÕES SOBRE A LEITURA VISTA PELA COGNIÇÃO
}

\author{
Maria Cristina Micelli Fonseca 1 \\ 1'Universidade Federal do Ceará, Fortaleza, Ceará, Brasil
}

\begin{abstract}
Resumo: O objetivo deste artigo é apresentar a tradutores, professores universitários, assim como para graduandos e graduados como o cérebro trabalha permitindo-nos extrair significado de um conjunto de letras sendo focadas pela fóvea sob o foco atencional: ler. A fim de iniciar os novatos a esse tópico, a introdução explica a relevância do assunto fornecendo dados do analfabetismo funcional no Brasil. Em seguida, descreve-se de forma resumida o rastreador ocular como ferramenta para medir as latências e mostrar as fixações dos olhos enquanto lemos. Logo após, são apresentadas as partes dos olhos ligadas à leitura. Finalmente, é exposto o processo de reconhecimento visual de uma palavra. Esses processos que são a base do mapeamento ortografia-som e ortografia-semântica, explicando que as palavras são decodificadas e analisadas em vários níveis. A relação funcional entre as variáveis ortográficas, fonológicas e semânticas são exploradas. Há um esforço de focar tanto no processamento interativo entre vários níveis, como na arquitetura e na dinâmica envolvida no reconhecimento visual da palavra.
\end{abstract}

Palavras-chave: Reconhecimento Visual da Palavra; Leitura; Psicolinguística

\section{NOTIONS ON READING VIEWED BY COGNITION}

\begin{abstract}
The objective of this article is to introduce to translators, professors as well as graduate and undergraduate students how the brain works to enable us to extract meaning from a string of letters being focused by the fovea under the attentional beam: to read. In order to initiate novice readers to the topic, the introduction explains the relevance of the matter by providing factual numbers of the functional illiteracy in Brazil. Secondly, a broad overview of the eye-tracker is provided as a tool to measure latencies and show the fixations of the eyes while reading.
\end{abstract}


Thirdly, parts of the eyes related to the reading skill are presented. At last, an account of the Visual Word Recognition is accorded describing the processes that support the mapping of spelling-to-sound spelling-tomeaning, emphasizing that words are coded and analyzed at multiple levels. The functional relationships between orthographic, phonological, and semantic variables are explored. There is an attempt to focus on both the interactive processing between different layers as well as the architecture and processing dynamics of the visual word recognition system.

Keywords: Visual Word Recognition; Reading; Psycholinguistics

\section{Introdução}

Aprender a ler é uma atividade vital no mundo moderno. Estima-se que o custo gerado pelas pessoas que não conseguem ser alfabetizadas na economia global seja da ordem de um trilhão de dólares todos os anos (Milledge \& Blythe). A razão disso é que a pessoa não alfabetizada acaba tendo dificuldade para se empregar, tem baixos salários, e acaba tendo que ser amparada por programas assistenciais públicos. Mesmo assim, o domínio dessa habilidade ainda não recebe a atenção que merece, seja do poder público ou da família.

Enquanto a língua falada é adquirida por todas as crianças com desenvolvimento normal, a leitura é uma habilidade aprendida que requer anos de prática e instrução formal. Para ler a criança precisa aprender associações entre as formas visuais de palavras escritas (ortografia) e, os sons da fala associados às letras e aos grafemas (fonologia), e os seus significados (semântica). Ler é uma invenção cultural, que está atrelada à(s) línguas(s) que a criança está exposta, e seu(s) sistema(s) ortográfico(s), que também é uma invenção cultural.

Como se pode ver, a leitura proficiente é um comportamento laborioso e multifacetado. O processo de leitura é extremamente complexo, compreendendo muitos níveis de representação. A informação visual é recebida pelos olhos e as propriedades ortográficas, fonológicas e morfológicas (geralmente são consideradas propriedades sublexicais, as representações menores que a palavra, 
como as letras, os morfemas, e os sons) da palavra são analisadas. Em seguida, as representações semântica e sintática (propriedades superlexicais) são acessadas e integradas ao significado da sentença em que a palavra aparece, e essa ao texto/contexto.

Desde que a psicologia passou a ser uma ciência autônoma no final do século XIX, entender os mecanismos funcionais que subjazem à leitura e como ela é aprendida têm sido alvo de inúmeras pesquisas; mais recentemente a psicolinguística moderna tem ampliado os campos de estudo, amparada pelos avanços da tecnologia e seu barateamento.

Muito se sabe sobre os fundamentos da aquisição da leitura pela criança na infância, no entanto, só recentemente esse conhecimento tem sido introduzido em políticas e práticas educacionais em alguns países verdadeiramente interessados na educação do seu povo.

No Brasil, pouquíssimos cursos de pedagogia e licenciatura introduziram disciplinas com base na cognição nas suas graduações. Segundo Borba, em 2012, nas regiões norte e centro-oeste do país, não havia nenhuma disciplina de fundo neurocientífico ligada à educação. Na região nordeste foram encontrados dois cursos, cinco no sudeste, e quinze no sul do país.

Até a metade do século passado, bastava ler e escrever para se estar alfabetizado. Segundo Ribeiro, a modernização das sociedades, o desenvolvimento tecnológico, a ampliação da participação social e política colocam demandas cada vez maiores com relação às habilidades de leitura e escrita. No Início da década de 70, a UNESCO sugere a adoção do critério alfabetismo funcional. A questão não é mais apenas saber se as pessoas conseguem ou não ler e escrever, mas também o que elas são capazes de fazer com essas habilidades, no Brasil convencionou-se chamar o indivíduo que possui estas habilidades de letrado. Ao mesmo tempo, nasce o alfabetismo: as capacidades de uso efetivo da leitura e escrita nas diferentes esferas da vida social. Da mesma forma, nasce o alfabetismo funcional: quanto o alfabetizado tem de letrado.

No que se refere à leitura e letramento, Eduardo Kenedy informa que a UNESCO estabeleceu um conjunto de critérios compor- 
tamentais afim de mensurar, em 3 níveis, o grau de alfabetização funcional de um indivíduo. A avaliação é feita através da simulação de situações cotidianas de uma sociedade letrada, nas quais a interpretação de input escrito é condição fundamental para que a pessoa exerça sua cidadania, correlacionando informações socioculturais e fazendo escolhas informadas. A partir dos resultados, a entidade estabeleceu 5 níveis (ver Quadro 1 abaixo) de alfabetização.

\section{Quadro 1 - níveis de alfabetização (funcional) (UNESCO 2015)}

\begin{tabular}{|c|c|}
\hline \multicolumn{2}{|r|}{ Quadro 3 - Escala de proficiência } \\
\hline Grupos & Escala especial para estudo Analfabetismo e mundo do trabalho \\
\hline $\begin{array}{l}\text { Analfabeto } \\
(0<X \leq 50)\end{array}$ & $\begin{array}{l}\text { - Corresponde à condição dos que não conseguem realizar tarefas simples que } \\
\text { envolvem a leitura de palavras e frases ainda que uma parcela destes consiga } \\
\text { ler números familiares (números de telefone, preços, etc.). }\end{array}$ \\
\hline $\begin{array}{l}\text { Rudimentar } \\
(50<X \leq 95)\end{array}$ & $\begin{array}{l}\text { - Localiza uma ou mais informações explícitas, expressas de forma literal em } \\
\text { textos muito simples (calendários, tabelas simples, cartazes informativos) } \\
\text { compostos de sentenças ou palavras que exploram situações familiares do } \\
\text { cotidiano doméstico. } \\
\text { - Compara, lê e escreve números familiares (horários, preços, cédulas/moedas, } \\
\text { telefone) identificando o maior/menor valor. } \\
\text { - Resolve problemas simples do cotidiano envolvendo operações matemáticas } \\
\text { elementares (com ou sem o uso de calculadora) ou estabelecendo relações } \\
\text { entre grandezas e unidades de medida. } \\
\text { - Reconhece sinais de pontuação (vírgula, exclamação, interrogação, etc.) pelo } \\
\text { nome ou função. }\end{array}$ \\
\hline $\begin{array}{l}\text { Elementar } \\
(95<X \leq 119)\end{array}$ & $\begin{array}{l}\text { - Seleciona uma ou mais unidades de informação, observando certas condições, } \\
\text { em textos diversos de extensão média realizando pequenas inferências. } \\
\text { - Resolve problemas envolvendo operações básicas com números da ordem } \\
\text { do milhar que exigem certo grau de planejamento e controle (total de uma } \\
\text { compra, troco, valor de prestações sem juros). } \\
\text { - Compara ou relaciona operações numéricas ou textuais expressas em gráficos } \\
\text { ou tabelas simples, envolvendo situações de contexto cotidiano doméstico } \\
\text { ou social. } \\
\text { - Reconhece significado de representação gráfica de direção e/ou sentido } \\
\text { de uma grandeza (valores negativos, valores anteriores ou abaixo daquele } \\
\text { tomado como referência). }\end{array}$ \\
\hline
\end{tabular}




\begin{tabular}{l|l}
\hline Intermediário & $\begin{array}{l}\text { - Localiza informação expressa de forma literal em textos diversos (jornalísticos } \\
\text { e/ou científico) realizando pequenas inferências. }\end{array}$ \\
& $\begin{array}{l}\text { Resolve problemas envolvendo operações matemáticas mais complexas } \\
\text { (cálculo de percentagens e proporções) da ordem dos milhões, que exigem } \\
\text { critérios de seleção de informações, elaboração e controle de situações } \\
\text { diversas (valor total de compras, cálculos de juros simples, medidas de área } \\
\text { e escalas). } \\
\text { - Interpreta e elabora sínteses de textos diversos (narrativos, jornalísticos, } \\
\text { científicos), relacionando regras com casos particulares a partir do } \\
\text { reconhecimento de evidências e argumentos e confrontando a moral da } \\
\text { história com sua própria opinião ou senso comum. } \\
\text { - Reconhe o efeito de sentido ou estético de escolhas lexicais ou sintáticas, de } \\
\text { figuras de linguagem ou sinais de pontuação. }\end{array}$ \\
\hline Proficiente & $\begin{array}{l}\text { Elabora textos de maior complexidade (mensagem, descrição, exposição ou } \\
\text { argumentação) com base em elementos de um contexto dado e opina sobre o } \\
\text { posicionamento ou estilo do autor do texto. }\end{array}$ \\
\hline - $\begin{array}{l}\text { Interpreta tabelas e gráficos envolvendo mais de duas variáveis, } \\
\text { compreendendo elementos que caracterizam certos modos de representação } \\
\text { de informação quantitativa (escolha do intervalo, escala, sistema de medidas } \\
\text { ou padrões de comparação) reconhecendo efeitos de sentido (ênfases, } \\
\text { distorções, tendências, projeções). } \\
\text { Resolve situações-problema relativos a tarefas de contextos diversos, que } \\
\text { envolvem diversas etapas de planejamento, controle e elaboração, que } \\
\text { exigem retomada de resultados parciais e o uso de inferências. }\end{array}$ \\
\hline
\end{tabular}

Fonte: Inaf

A Constituição Brasileira de 1988, no seu artigo 205 prevê que: "A educação, direito de todos e dever do Estado e da família, será promovida e incentivada com a colaboração da sociedade, visando ao pleno desenvolvimento da pessoa, seu preparo para o exercício da cidadania e sua qualificação para o trabalho". A lei maior do país coloca como dever do estado prover seus cidadãos da capacidade de utilizar a linguagem em todas as suas nuances, até terminarem o Ensino Médio. Para que os brasileiros possam exercer a cidadania, que inclui viver amplamente em sociedade, é necessário que todos terminem o Ensino Médio (EM) completamente letrados. O objetivo final prevê que, uma vez findo os 12 anos de escolaridade, todos os brasileiros possam ter a oportunidade de continuar a se desenvolver 
pessoal e profissionalmente (Ribeiro), acompanhando as mudanças socioeconômicas que se sucedem durante a vida útil dos indivíduos.

Quadro 2 - Distribuição do Alfabetismo

\begin{tabular}{l|l|l}
\hline Grupo & $\%$ & $\mathbf{N}^{0}$ de respondentes \\
\hline Analfabeto & $4 \%$ & 88 \\
\hline Rudimentar & $23 \%$ & 457 \\
\hline Elementar & $42 \%$ & 843 \\
\hline Intermediário & $23 \%$ & 453 \\
\hline Proficiente & $8 \%$ & 161 \\
\hline Total & $100 \%$ & 2.002 \\
\hline $\begin{array}{l}\text { Analfabeto+rudimentar } \\
\text { analfabetos funcionais }\end{array}$ & $27 \%$ & 545 \\
\hline $\begin{array}{l}\text { Elementar, intermediário e proficiente: } \\
\text { alfabetizados funcionalmente }\end{array}$ & $73 \%$ & 1.457 \\
\hline
\end{tabular}

Fonte: Inaf

Observa-se que dos $27 \%$ considerados analfabetos funcionais, apenas 4\% são efetivamente analfabetos (ver Quadro 2 acima). Esse grupo, geralmente, apresenta pessoas mais velhas. Quando se compara pela escolaridade, o estudo aponta $48 \%$ dos que terminaram o EM, $48 \%$, cerca da metade, ainda se encontram no nível Elementar, e 11\%, no nível Rudimentar (ver Quadro 3 abaixo).

Segundo, ainda, o relatório do Inaf (Índice de Analfabestimo Funcional) do grupo que chegou até a universidade ou graduou-se, apenas $22 \%$ estão no último nível da escala de proficiência. Desse grupo, $42 \%$ se encontram no nível Intermediário e $32 \%$ no Elementar. O mais inquietante é que apenas $9 \%$ dos que terminam o EM estão no nível Proficiente. 
Quadro 3 - Distribuição do alfabetismo e escolaridade

\begin{tabular}{|c|c|c|c|c|c|c|c|}
\hline \multirow{2}{*}{$\begin{array}{l}\text { Base } \\
\text { Nenhuma }\end{array}$} & \multicolumn{2}{|l|}{$\begin{array}{l}\text { Total } \\
2.002\end{array}$} & \multirow{2}{*}{$\begin{array}{l}\text { Analfabeto } \\
\mathbf{8 8} \\
59 \%\end{array}$} & \multirow{2}{*}{ 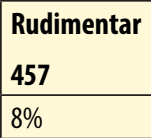 } & \multirow{2}{*}{\begin{tabular}{|l|}
$\begin{array}{l}\text { Elementar } \\
843\end{array}$ \\
$1 \%$ \\
\end{tabular}} & \multirow{2}{*}{\begin{tabular}{|l|} 
Intermediário \\
$\mathbf{4 5 3}$ \\
$0 \%$ \\
\end{tabular}} & \multirow{2}{*}{\begin{tabular}{|l|} 
Proficiente \\
161 \\
$0 \%$ \\
\end{tabular}} \\
\hline & 97 & $5 \%$ & & & & & \\
\hline $\begin{array}{l}\text { Ens. Fund. } \\
\text { Anos iniciais }\end{array}$ & 320 & $16 \%$ & $30 \%$ & $37 \%$ & $12 \%$ & $4 \%$ & $2 \%$ \\
\hline $\begin{array}{l}\text { Ens. Fund. } \\
\text { Anos finais }\end{array}$ & 459 & $23 \%$ & $10 \%$ & $32 \%$ & $29 \%$ & $11 \%$ & $7 \%$ \\
\hline Ens. Médio & 795 & $40 \%$ & $1 \%$ & $20 \%$ & $45 \%$ & $55 \%$ & $45 \%$ \\
\hline $\begin{array}{l}\text { Ed. Superior } \\
\text { ou mais }\end{array}$ & 331 & $17 \%$ & $0 \%$ & $3 \%$ & $13 \%$ & $31 \%$ & $45 \%$ \\
\hline Total & 2.002 & $100 \%$ & $100 \%$ & $100 \%$ & $100 \%$ & $100 \%$ & $100 \%$ \\
\hline
\end{tabular}

Fonte: Inaf

Segundo Leonor Scliar-Cabral, para se melhorar a qualidade da educação em leitura e escrita, temos de começar onde elas começam: na alfabetização. Ainda segundo ela, é necessário que o professor detenha fundamentos científicos sólidos para entender as habilidades cognitivas de ler e escrever, e como se dá o processo da aquisição da leitura do ponto de vista da cognição, do cérebro.

Diante da importância da habilidade de ler proficientemente, esse artigo trata de um aspecto cognitivo do ato de ler. Nele abordamos a Hipótese da Qualidade Lexical (Perfetti), tratando o processo pelo qual nós, seres humanos, identificamos uma cadeia de letras impressas como sendo uma palavra, no seu sentido mais vulgar e computamos o seu significado: o reconhecimento visual da palavra.

Dada a importância do reconhecimento da palavra durante a leitura, descrevemos, na seção 2, os conceitos de herança lexical e de Hipótese da Qualidade Lexical; na seção 3, apresentamos uma breve descrição do papel do rastreador ocular na investigação do reconhecimento de palavras, e quais são as medidas colhidas por ele. Em seguida, na seção 4, abordamos abreviadamente diversos resultados de pesquisas ligadas ao reconhecimento visual da palavra, que se serviram de rastreadores oculares; por problema de espaço, não mencionando muitos estudos cujos resultados foram 
dando forma ao que hoje constitui o reconhecimento visual da palavra. Este trabalho visa dar a conhecer, pelo menos uma parcela daqueles que trabalham com a leitura, no que consiste identificar a palavra. Pretendemos divulgar, mesmo que infimamente, o arcabouço teórico-experimental que ampara a posição dos autores citados nessa introdução: Leonor Scliar-Cabral, Charles Perfetti e Kate Nation. Esses autores, entre outros, estudam a leitura pelo viés da Neurociência.

Kate Nation abre seu artigo na revista Science of Learning com o título: "Nurturing a lexical legacy: Reading experience is critical for the development of word Reading skil" [Cultivando a herança lexical: A experiência da leitura é crucial para o desenvolvimento da habilidade de ler palavras]. A hipótese da Herança Lexical defende a leitura das palavras, ciente de que ler proficientemente é muito mais que isso, mas que sem a leitura eficiente dessas, não há como se atingir a leitura competente.

Segundo a autora, é necessário entender que a experiência em leitura se desenvolve através da aprendizagem de palavras, sejam escritas ou orais, em contextos significativos. Aprender a ler nas línguas alfabéticas consiste, essencialmente, em entender como as letras (ou grafemas) se relacionam com os sons (ou fonemas), permitindo à criança aprender a acessar a forma sonora da palavra escrita, e, assim, compreender como se reconhece as palavras, que já eram conhecidas, agora na forma grafada. Ela acrescenta que, para tornar uma criança um leitor proficiente, é fundamental a experiência. Leitura, como qualquer habilidade aprendida, precisa de prática. Uma vez que a criança aprendeu a decodificar os grafemas, é a prática de ler que vai permitir o aprimoramento da habilidade recém-aprendida, provendo o mapeamento entre ortografia e fonologia, aumentando a frequência com que uma palavra é lida, o que vai facilitar seu processamento, como veremos mais abaixo. A exposição à palavra escrita permite a formação de uma criança que lê sem dificuldades, e um adulto, leitor proficiente.

Perfetti e Hart ((a); (b)) propuseram a Hipótese da Qualidade do Léxico com base no modelo de Experiência Vocabular de 
Reichle e Perfetti. Ela se apoia na premissa que a representação mental de uma palavra contém sua forma sonora, gráfica e o seu sentido altamente associados. Esses constituintes ortográficos, fonológicos, morfológicos e semânticos formam a identidade dessa palavra. Eles explicam que as nossas representações das palavras podem ter níveis diferentes de qualidade. O conhecimento ortográfico preciso de um vocábulo acelera o processo de identificação das palavras durante a leitura (Andrews \& Hersch), principalmente no que tange os vizinhos ortográficos (palavras que se assemelham, com apenas 1 ou 2 letras de diferença). Este tópico será abordado mais adiante. As palavras cujas representações mentais têm qualidade superior são aquelas que identificamos rapidamente durante a leitura, liberando recursos cognitivos para o objetivo final da leitura: compreensão.

Tanto Perfetti e colegas, quanto Nation deixam claro que embora a compreensão de texto requeira mais do que ler palavras, é a habilidade de leitura de palavras que é o início, quando se aprende ortografia, e quando se dá à criança a possibilidade de inserção no mundo da escrita, dando subsídios para a experiência em leitura, ou seja, o ato de praticar essa habilidade adquirida, é que fará a diferença entre bons e maus leitores.

Os Estudos da Tradução também tem focado na tradução pelo viés da cognição. O maior pesquisador nessa área no Brasil é o Prof. Dr. Fábio Alves, da UFMG. O professor investiga sobre a sobrecarga cognitiva em tradução, que com certeza envolve estudar a habilidade de leitura, e se utiliza do rastreador ocular para acompanhar o processamento na leitura no ato de traduzir. Na área de Linguística Aplicada, também com ênfase em Estudos da Tradução, o professor realiza pesquisas experimentais sobre o processo de tradução e sobre a aquisição de competências em tradução.

Nesse trabalho, a ênfase é dada à leitura tradicional, no texto estático no papel, mas os Estudos da Tradução também focam na leitura de legendas, na leitura de textos digitais, e também na leitura de hyperlinks. A seguir falamos sobre a relação cognição e leitura que envolve o rastreador ocular. 


\section{Medindo o movimento dos olhos}

A técnica de rastreamento ocular vem de longa data, no entanto, somente recentemente os aparelhos se tornaram não-invasivos. $\mathrm{O}$ rastreamento por vídeo, usado pela maioria dos rastreadores disponíveis no mercado, detecta os reflexos da pupila e da córnea gerados a partir da emissão de luz infravermelha. A imagem dos olhos é gravada em intervalos regulares por uma câmera, que filma os olhos do participante enquanto ele lê naturalmente. Essas amostras de imagem são analisadas e, fornecem uma série de medidas à escolha do pesquisador (Forster).

$\mathrm{O}$ interesse pelo rastreamento ocular na pesquisa cognitiva vem da pressuposição de que, ao direcionar o olhar para um determinado ponto, o sujeito direciona também seus recursos cognitivos para esse ponto, com o objetivo de processar as informações ali disponíveis. Just e Carpenter, a partir de um estudo de rastreamento de leitura no inglês, formalizaram a relação entre movimentos oculares e o processamento cognitivo, sugerindo que o comportamento oculomotor reflete diretamente a complexidade do processamento cognitivo subjacente. Essa hipótese se baseia na observação de que tempos maiores de fixação (ou seja, períodos nos quais o leitor se detém mais prolongadamente sobre uma palavra) estão associados tanto a palavras menos frequentes, quanto a palavras mais longas, ou à complexidade do texto sendo lido, sugerindo uma correlação entre o input linguístico e o tempo de fixação (processamento).

Just e Carpenter propuseram que o leitor começa a interpretar a palavra assim que os olhos se fixam sobre ela. Ainda segundo os autores, essa intepretação incluiria o processamento linguístico, que vai da ortografia e da fonologia à sintaxe e à semântica. Hoje sabe-se que o tempo de fixação em uma palavra não precisa necessariamente estar relacionado ao seu processamento apenas, mas pode ser consequência do processamento da palavra anterior, fenômeno conhecido como spillover. Há também controvérsias no que tange o processamento de todos os níveis linguísticos, do grafo-fonológico ao semântico, na primeira fixação. Contudo, há 
consenso que o processamento se inicia logo na primeira fixação, e que o comportamento ocular que se segue refletirá as dificuldades encontradas na forma de tempo de duração da fixação, número de fixações, inclusive a direção e a extensão das sacadas (quando o olho vai de uma palavra a outra).

Dessa forma, as medidas colhidas pelo rastreador ocular visam refletir o processamento. O aparelho permite coletar vários tipos de medidas que visam espelhar o processamento. A escolha dessas vai de acordo com os objetivos do pesquisador. Aqui vamos elencar apenas algumas delas. Quando o objetivo da pesquisa experimental é medir o tempo de fixação em cada palavra, utiliza-se first-fixation-duration (FFD), que mede o tempo da primeira vez que os olhos pousam sobre a palavra. Se o objetivo é conhecer o tempo total despendido sobre uma palavra, usa-se gaze duration (GD), que apresenta a soma do tempo de todas as fixações antes que os olhos mudem para outra palavra à direita. Quando o intuito é saber o tempo total de fixação em uma palavra, incluindo eventuais regressões sobre ela, emprega-se total fixation duration (TFD).

Quando da fixação, toda a área visualizada é conhecida como campo visual. Esse se divide em três partes, de acordo com a acuidade de percepção do olho humano proporcionada pela incidência de luz na retina, a saber: região foveal, parafoveal e periférica. Esses nomes se referem às áreas da retina onde há incidência de luz. A fóvea é a área que oferece maior nitidez na fixação, essa precisão permite o processamento de detalhes quando da extração de informações do estímulo, abrangendo 2 graus de ângulo visual, o equivalente a 7-9 (zona parafoveal).

Ao ler este texto, você deve imaginar que seus olhos deslizam suavemente sobre as palavras, uma após a outra, linearmente. Contudo, o estudo dos movimentos oculares mostrou que isso é uma ilusão. Na verdade, nossos olhos avançam sobre a linha do texto de forma descontínua (Rayner \& Pollatsek). Durante a leitura, os nossos olhos ou se mantém relativamente estáveis, as chamadas fixações, por cerca de 200 a 250 milisegundos (ms), em média, ou se movem através de saltos entre as fixações, conhecidos como 
sacadas. Nestes saltos, nossos olhos pulam cerca de 7 a 9 letras ou espaço de igual dimensão, da esquerda para a direita, para leitores de línguas alfabéticas ocidentais. Esses movimentos sacádicos são rápidos, levam cerca de 20 a $35 \mathrm{~ms}$, e acontecem de forma balística, ou seja, uma vez iniciado o movimento, não há como alterá-lo. Ao pousar, ocorrem as fixações, quando a informação é efetivamente extraída da palavra impressa/escrita. Durante os movimentos sacádicos, não adquirimos nenhuma informação, nem percebemos qualquer alteração no texto que aconteça durante o movimento dos olhos, fenômeno conhecido como supressão sacádica (Matin).

Além disso, imaginamos que os movimentos dos olhos são sempre avante, todavia, entre $10 \%$ e $15 \%$ dos movimentos são regressivos, chamados de sacadas regressivas, ou regressões. Elas costumam ser curtas, voltando apenas alguns caracteres à esquerda, ao início da palavra sendo lida ou ainda à palavra anterior a ela. Frequentemente, essas regressões menores que 10 letras não refletem dificuldade de compreensão, mas são correções do sistema oculomotor.

As regressões podem ser refixações, e, nesse caso, demonstram dificuldade na leitura. A regressão a uma palavra anterior, já fixada, aponta que essa precisa ser processada novamente. Os leitores geralmente só se dão conta de regressões mais longas, com a finalidade de elucidar alguma confusão no entendimento do texto. Quando o texto é fácil de ler, um leitor proficiente pode ler entre 200 a 350 palavras por minuto; sua sacada média é de 7 a 9 letras ou espaço delas.

Outra ilusão que se tem é que todas as palavras recebem fixações, quando na verdade, $30 \%$ das palavras de um texto, em média, são puladas (Rayner, (g); (h)). Geralmente, as palavras puladas são curtas tais como: de, a, o, um, uma, para. Porém, palavras longas também podem ser puladas, se forem altamente previsíveis (Rayner; et al.; (e)).

Outro ponto importante sobre o movimento dos olhos durante a leitura diz respeito à posição dos olhos sobre o texto. Por muito tempo se acreditava que os olhos estavam alinhados na mesma posição ao pousarem sobre uma palavra. No entanto, $50 \%$ das vezes os olhos estão sobre letras diferentes de uma palavra. 
Há evidências de que as palavras puladas foram processadas enquanto os olhos ainda estavam fixados na palavra anterior. Foram lidos pela parafóvea. Enquanto a fóvea está fixada em uma palavra, a parafóvea inicia o processo de reconhecimento da palavra ao lado. Falaremos mais a respeito quando falarmos do reconhecimento da palavra logo abaixo.

A fóvea executa a maior parte do trabalho dos olhos para identificar uma palavra. No entanto, um dos pontos mais estudados pela psicolinguística na última década é saber quanta informação a parafóvea consegue extrair da palavra à frente da palavra-foveal.

Os resultados de pesquisas sobre o papel da parafóvea foram consistentes em alguns pontos, contudo, em outros há muita controvérsia. Vejamos primeiro os papéis da parafóvea em que há mais consenso entre os pesquisadores. Estão visíveis para a parafóvea à direita da palavra sendo fixada, 7 a 8 letras que estão sendo identificadas pela parafóvea, enquanto a fóvea se ocupa da palavra sendo fixada, a parafóvea começa a análise da palavra à direita. Esse fenômeno ficou conhecido como a pré-visualização parafoveal (Schotter; et al.).

O Benefício da Pré-Visualização parafoveal obteve resultados bem robustos. Pesquisas usando o Paradigma do Limite (Rayner, (a)) mudavam as letras da palavra parafoveal, por letras semelhantes (trocando t por 1, por exemplo), ou não semelhantes (Hyona; et ali). O resultado apontou que, quando as letras não eram semelhantes à da palavra-alvo, o tempo de fixação dessa palavra, agora sob a fóvea, era 40ms maior do que a fixação da palavra-alvo. Quando as letras eram semelhantes, o custo da fixação era de $15 \mathrm{~ms}$. O fato de ser mais custoso a fixação aponta que o que foi processado pela parafóvea não pode ser utilizado quando da chegada da fóvea sobre a palavra-alvo. O fato de inibir o que havia sido processado e iniciar a identificação novamente custou $40 \mathrm{~ms}$ a mais do que a pré-visualização com a palavra-alvo. Sendo as letras parecidas, o custo foi menor.

Observa-se que o processamento da parafóvea tem um papel importante na leitura. A controvérsia reside na extensão de quanta in- 
formação já foi processada quando a fóvea fixa na palavra-alvo. $\mathrm{O}$ aumento do tempo de processamento da fóvea devido à parafóvea é chamado de Efeitos da Parafóvea sobre a Fóvea. Indaga-se também se o processamento da fóvea e da parafóvea acontece em paralelo ou serialmente, ou seja, ao mesmo tempo ou um depois do outro?

Conhecendo agora como os olhos trabalham, vamos finalmente conhecer como eles visualizam a palavra para que o cérebro, ao receber este estímulo, prossiga com o processamento, uma palavra depois da outra, o que conhecemos como leitura.

\section{O Reconhecimento visual da palavra}

A competência de reconhecer as palavras é, possivelmente, a habilidade mais importante a ser desenvolvida quando se aprende a ler. O reconhecimento automático das palavras permite ao leitor empregar os seus recursos cognitivos somente com as estruturas semânticas e sintáticas do texto, assim como com a integração da informação. Quando há dificuldade no processamento das palavras, a leitura se torna lenta e trabalhosa, a demanda de mais recursos cognitivos nessa fase implica em prejuízo na compreensão, tornando a leitura não-prazerosa. Conhecer as palavras, ou seja, ter domínio do vocabulário é primordial para a compreensão do texto. Acredita-se que esse conhecimento seja responsável pelas diferenças individuais na performance da leitura no período escolar.

A leitura competente é uma conquista importante, pois o processamento da leitura é composto por vários níveis de representação.

$\mathrm{O}$ artigo de Scliar-Cabral deixa entrever que a maioria das pessoas sabe muito pouco sobre uma das habilidades mais importantes adquiridas habitualmente na escola. Mais preocupante é que os professores responsáveis pelo ensino da leitura conheçam muito pouco sobre os processos cognitivos que subjazem a habilidade que pretendem ensinar. $\mathrm{O}$ ato de ler parece trivial, mas é complexo, e envolve prática para o seu desenvolvimento pleno. Em um país com alto índice de analfabetos funcionais, está mais do que na hora 
de tornar de conhecimento geral os processos envolvidos na leitura, e como se consegue bons leitores.

\subsection{Reconhecendo letras dentro das palavras: a ortografia}

Embora ainda chamem esse processo de acesso lexical, ou acesso ao Léxico Mental, acredita-se hoje que a informação ortográfica esteja armazenada separadamente do significado e da sua forma sonora (Rastle; (a)). O reconhecimento da palavra requer o acesso às letras que as compõem, as representações ortográficas. As letras são vistas como identidades abstratas (grafemas); suas representações individuais, como as do quadro abaixo, são reconhecidas independentemente da fonte, da cor, do tamanho, de estarem escritas em maiúscula ou minúscula, em letra bastão ou manuscrita (Figura 1).

Figura 1 - Exemplo de estímulo visual que identifica a identidade abstrata da letra, no caso aqui "f".

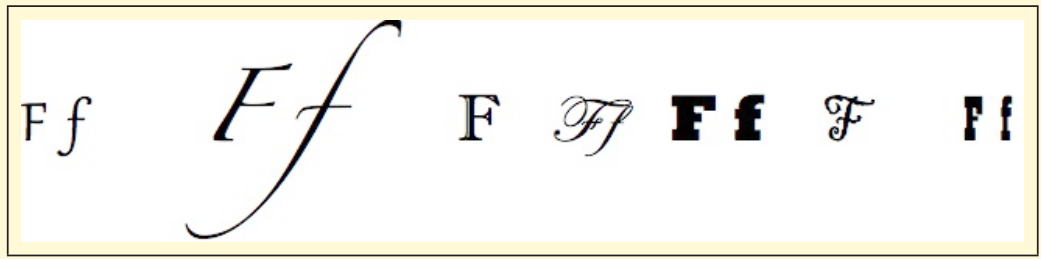

Fonte: Inaf

Além da identidade da letra, é necessário atentar para a posição da letra na palavra, de outra forma os leitores não saberiam se leram AMOR, ROMA, MORA ou MARO (Carr, T. et al.). Assume-se que exista um número de encaixes para cada palavra, onde as letras se colocam na ordem. No entanto, estudos sugerem que nas línguas indo-europeias a posição da letra parece poder ser contornada, se as primeiras letras e as últimas forem preservadas. Por exemplo: a palavra SANDUÍCHE pode ser reconhecida escrita como SANUDICHE, mas fica mais difícil se for SANTISCOPE. 
Porém, em línguas que apresentam anagramas, como o hebraico, a pequena mudança na parte interna da palavra leva a não identificação dessa. Conclui-se que esta característica não é universal.

\subsection{Frequências das palavras}

Quanto mais frequente for a palavra, mais rápida será sua identificação na leitura. A experiência lexical de que falamos na primeira seção, se deve ao fato de que, quanto mais frequente for a representação ortográfica, mais fácil será acessar sua representação. Estima-se a frequência de uma palavra através de corpora. Acredita-se que quanto maior o número de contextos em que uma palavra aparece, mais familiar ela será.

Há trabalhos cujos dados corroboram que a idade da aquisição da palavra interfere na velocidade do acesso: quanto mais cedo aprender, mais fácil seria o acesso ortográfico. No entanto, muitos admitem que frequência e idade da aquisição são, na verdade, duas dimensões da mesma variável. Os efeitos da frequência parecem ser cumulativos, ou seja, a frequência com que o indivíduo foi exposto a uma determinada palavra durante a vida. De toda forma, a nossa experiência com as palavras e como são escritas promovem o desenvolvimento da representação ortográfica, como mencionado na seção 1 .

\subsection{Morfologia}

A maioria das línguas do mundo é construída pela combinação de representações morfológicas. Rastle (a) apresenta pesquisas em que foi constatado que a criança reconhece os morfemas de uma palavra, e esse reconhecimento influencia no tempo do seu processamento. A autora dá como exemplo um trabalho de priming realizado na língua inglesa, quando o reconhecimento da palavra-alvo "dark" foi facilitado pela apresentação mascarada da palavra "darkness". A autora conclui que os dados sugerem que as representações ortográficas são armazenadas na forma de morfemas, uma vez que os leitores ativaram os morfemas da palavra durante o reconhecimento. 


\subsection{O Tamanho da palavra importa}

O comprimento da palavra, ou seja, o número de letras que ela apresenta interfere na identificação da palavra durante a leitura, observa-se uma latência maior para palavras mais longas. Não é exatamente uma surpresa, pois a fóvea oferece uma boa acuidade apenas nas letras que estão ao seu alcance, entre 7 e 9 letras. A medida GD, colhida pelo rastreador ocular, permite dimensionar que palavras mais longas têm um tempo de fixação maior, pois como o final da palavra não estava nítido, é necessária uma refixação na mesma palavra.

\subsection{Efeito dos vizinhos ortográficos}

Vizinhos ortográficos são as palavras semelhantes à palavra-alvo. Max Coltehart et al. definiu o tamanho do estimulo (N) como o número de palavras do mesmo comprimento que podem ser criadas mudando-se apenas uma letra da palavra-alvo. Se um conjunto de letras é semelhante a muitas palavras, esse conjunto ativará múltiplos candidatos, criando um efeito inibitório no processamento do estímulo, ou seja, aumentando o tempo de processamento.

\subsection{Influência fonológica no reconhecimento}

Estudos conduzidos em inglês, com informantes falantes da língua inglesa, mostraram que a parte fonológica da palavra cuja pronúncia influi no tempo de processamento da mesma (Sereno \& Rayner). Estudos conduzidos em inglês, mostrou que quando liam palavras cuja pronúncia era irregular, (como pronúncia irregular podemos exemplificar no português brasileiro a palavra festa, que tem a pronúncia do "e" aberta), o tempo de processamento era maior, o que indica que se ativa o som das palavras mesmo lendo em silêncio. O efeito aparece na FFD, mas não mais no GD, apontando que o efeito é curto. O mesmo estudo feito com palavras de baixa frequência obteve um tempo maior de processamento, 
atingindo a GC. Isso sugere que a decodificação de palavras com baixa frequência requer mais o uso da parte fonológica da palavra.

Esses estudos sustentam a premissa de Nation e Hart \& Perfetti que a experiência em ler torna a leitura mais rápida. Quanto mais palavras a pessoa souber, menos palavras infrequentes ela vai encontrar.

\subsection{Palavras com Mais de um Sentido}

Pesquisas têm apontado que homônimos causam efeitos diferentes, dependendo da frequência deles (Binder, Katherine e Morris). Quando as duas palavras são balanceadas, ou seja, têm frequências semelhantes, o tempo de processamento é maior se comparado a uma palavra que não tem um homônimo. Quando uma palavra homônima é mais frequente do que a outra, se o sentido da sentença favorece a palavra infrequente, haverá um custo, ou seja, o tempo de processamento será maior, porque o sentido da palavra frequente será acessado primeiro e precisará ser inibido.

\section{Conclusão}

A leitura é a principal ferramenta na formação de um tradutor. Além disso, a eficiência nesse processo cognitivo é crucial para uma boa tradução. Como já mencionado, a leitura é uma habilidade que requer aprendizagem formal. E isso pode se transformar em uma dificuldade para a criança em fase escolar e muito mais para um adulto analfabeto (Rayner et al. (f)).

Neste artigo, foram apresentadas informações sobre a realidade do país em relação a essa habilidade tão necessária: a leitura. Vimos os números que denunciam o insucesso da educação básica no país, ficando evidente o descaso com que a alfabetização é tratada no país, e as consequências funestas que ela provoca.

Falamos sobre a importância de aprender a ler e praticar a leitura, focando nos trabalhos de Perfetti e Nation: Qualidade Lexical e Herança Lexical. Apresentamos o rastreador ocular e o movimento 
dos olhos durante a leitura, para finalmente nos determos no reconhecimento visual da palavra.

Compreender a leitura com base nos seus processos cognitivos é fundamental para que possamos interceder, e tentar minorar os efeitos da má alfabetização, que assombram muitos alunos durante toda a sua vida escolar, sem que eles estejam ao menos cientes de qual é, possivelmente, o verdadeiro problema do seu desempenho escolar. Assim talvez possam, eventualmente, se recuperar, e exercer, finalmente, a cidadania que a Constituição lhes promete.

\section{Referências}

Andrews, Sally e Jolyn Hersch "Lexical Precision in Skilled Readers: Individual differences in masked neighbor priming". Journal of Experimental Psychology: General. 139. 2 (2010): 299-318.

Binder, Katherine S.; Morris, Robin. "Eye Movement and lexical ambiguity resolution. Effects of prior encounter and discourse topic". Journal of Experimental Psychology: Learning, Memory and Cognition. 21.5, (1995): 1186-1196.

Borba, Valquíria Claudete Machado. "Cognição e Ensino-Aprendizagem da Teoria à Prática”. Letras em Revista. 10, (2019): 174-190.

Braze, David; Gong, Tao. "Orthography, Word Recognition, and Reading”. The Handbook of Psycholinguistics, Fernández, Eva M. e Helen Smith Cairns. (Eds.). 2018, pp. 270-293.

Bridgeman, B. "Eye Movements". Encyclopedia of Human Behavior, Ramachandran, V. S. (Ed.). 2a. ed. Amsterdam: Elsevier. 2012, pp. 160-166.

Cad. Trad., Florianópolis, v. 40, $\mathrm{n}^{0}$ esp. 2, p. 125-148, set-dez, 2020.143 
Carr, T.; et al. "Perceptual flexibility in word recognition: Strategies affect orthographic computation but not lexical access". Journal of Experimental Psychology: Human Perception and Performance. 4, (1978): 674-690.

Coltheat, Max; et al. "Access to the internal lexicon". Attention and Performance VI, Dornic, S. (Ed.). (1977): 535-555.

Copeland, Leana; Gedeon, Tom. "Measuring Reading Comprehension using Eye Movements". $4^{\text {th }}$ IEE International Conference on Cognitive Infocommunications. Budapest, Hungary. December, (2013): 791-796.

Drieghe, Denis. "Parafoveal-on-foveal effects on eye movements during reading". The Oxford Handbook of Eye Movements, Liversedge, Simon P. et al. (Eds.). Oxford e Nova York: Oxford University Press. 2011, pp. 884-855.

Forster, Renê. "Eye-tracking in psycholinguistic research". DELTA. 33.2, (2017): 609-644. 23/04/2020. <https://doi.org/10.1590/0102-445095461720767529>.

Hyona, Jukka; et al. "Are long compound words identifies serially via constituents? Evidence from eye movement contingent display change study". Memory and Cognition. 32, (2004): 523-532.

Hawelka, Stefan; et al. "On forward inferences of fast and slow readers. An eye movement study". Scientific reports. 5, (2015): 8432. 23/04/2020. < https:// www.nature.com/articles/srep08432\#citeas $>$.

Hyona, Jukka. "Foveal and parafoveal processing during reading". The Oxford Handbook of Eye Movements, Liversedge, Simon P. et al. (Eds.). Oxford e Nova York: Oxford University Press. 2011, pp. 820-838.

INAF. "EstudoEspecialsobreAlfabetismoeMundodoTrabalho".(2016).23/04/2020 $<$ https://drive.google.com/file/d/0B5WoZxXFQTCRRWFyakMxOTNyb1k/ view $>$.

Just, Marcel; Carpenter, Patricia. "A Theory of Reading: from Eye Fixations to Comprehension”. Psychological Review. 87.4, (1980): 329-354. 
Kenedy, Eduardo. "O Problema do Analfabetismo Funcional no Brasil sob Uma Análise Psicolinguística". Psicolinguística e educação, Maia, Marcus. (Ed.). Campinas, São Paulo: Mercado de Letras. 2018, pp. 81-102.

Luegi, Paula; et al. "Using Eye-tracking to detect reading difficulties". Journal of Eyetracking, Visual Cognition and Emotion. 1.1, (2011): 41-49.

McClung, A. Nicola; et al. "Orthographic and development of visual word recognition". Vision Word Recognition. Vol. II, Meaning and Context, Individuals and Development, Adelman, James S. (Org.). Nova York: Psychology Press. 2012, pp. 173-195.

Milledge, Sara; Blythe, Hazel. "The Changing Role of Phonology in Reading Development". Vision. 3.2, (2019). 23/04/2020. < https://www.mdpi.com/2411$5150 / 3 / 2 / 23>$.

Natin, Ethel. "Saccadic suppression: a review and an analysis". Psychological bulletin. 81, (1974): 899-217.

Nation, Kate. "Nurturing the lexical legacy: Reading experience is critical for the development of word reading skill". Science of Learning . 2, (2017). 23/04/2020. $<$ https://www.nature.com/articles/s41539-017-0004-7> .

Perea, Manuel. "Neighborhood Effects in Visual Word Recognition and Reading". The Oxford Handbook of Reading, Pollatsek, Alexander e Rebecca Treiman. (Eds.). Oxford, Nova York: Oxford University Press. 2015, pp. 76-87.

Perfetti, Charles A. "Reading Ability: Lexical Quality to Comprehension". Scientific Studies of Reading. 11.4, (2007). 23/04/2020. < https://www. researchgate.net/publication/254312976_Reading_Ability_Lexical_Quality_to_ Comprehension $>$.

Perfetti, Charles A. "The Representation Problem in Reading Acquisition". Reading acquisition. In: Gough, Philip B. Lawrence Erlbaum Associates, Inc. (1992): 145-174. 
Perfetti, Charles A.; Hart Leslie (a). "The lexical bases of comprehension skill”. Reading Acquisition, Gough, Philip B.; Lawrence Erlbaum Associates, Inc. (1992): 67-86.

Perfetti, Charles A.; Hart, Leslie (b). "The Lexical Quality Hypothesis". Precursors of functional literacy, Verhoeven, Ludo; et al. Amsterdam: John Benjamins. 2002, pp. 189-213.

Perfetti, Charles A.; et al. "The Acquisition of Reading Comprehension Skill". Blackwell handbooks of developmental psychology. The science of reading: A handbook, Snowling, Margareth J. e Charles Hulmes. (Eds.). Hoboken: Blackwell Publishing. 2005, pp. 227-247.

Rastle, Kathleen. "Visual Word Recognition". Neurobiology of Language. Hickok, Gregory e Steven L. Small. (Eds.). London: Academic Press. 2016, pp. 255-264.

Rastle, Kathleen (a). "Visual Word Recognition". The Oxford Handbook of Psycholinguistics, Rueschemeyer, Shirley-Ann e M. Gareth Gaskell. (Eds.). Oxford: Oxford University Press. 2a. ed. 2018, pp. 48-70.

Rastle, Kathleen (b). "The place of morphology in learning to read in English". Cortex. 116, (2019): 45-54.

Rayner, Keith (a). "The perceptual span and peripheral cues in reading”. Cognitive Psychology. 7, (1975): 65-81.

Rayner, Keith; et al. (b). "Eye Movements During Reading". The Science of Reading: A Handbook, Snowling, Margareth J. e Charles Hulmes. (Eds.). Amsterdam: Blackwell Publishing. 2005, pp. 79-97.

Rayner, Keith; et al. (c). "Eye movements as Reflections of Comprehension Processes in Reading”. Scientific Studies of Reading. 10.3, (2006): 231-255.

Rayner, Keith; et al. (d). "Eye Movements, the perceptual span, and reading speed”. Psychonomic Bulletin \& Review. 17.6, (2010): 834-839. 
Rayner, Keith; et al. (e). "Eye movements of older and younger readers when reading disappearing text". Psychology and Aging. 26.1, (2011): 214-223.

Rayner, Keith; et al. (f). The psychology of reading. Nova York e Londres. Amsterdam: Psychology Press. 2a. ed., (2012).

Rayner, Keith (g). "Eye Movements in Reading and Information Processing: 20 Years of Research". Psychological Bulletin. 124.3 (1998): 372-422.

Rayner, Keith (h). "The thirty fifth Sir Frederick Balett lecture: Eye Movements and attention in reading, scene perception and visual search". Quarterly Journal of Experimental Psychology. 62, (2009): 1457-1506.

Ribeiro, Vera Masagão. "Analfabetismo e alfabetismo funcional no Brasil". Psicolinguística e educação. 27/04/2020. <http://www.stellabortoni. com.br/index.php/artigos/1231-aoalfabitismo-i-alfabitismo-fuoiiooal-oobaasil-49609375>.

Reichle, Erik D.; Perfetti, Charles A. "Morphology in Word Identification: A Word-Experience Model That Accounts for Morpheme Frequency Effects". Scientific Studies of Reading. 7.3, (2003): 219-237.

Sereno, Sara C.; Rayner Keith. "Spelling-sound regularity effects on eye fixations in reading”. Perception and Psychophysics. 62, (2000): 402-409.

Schotter, Elizabeth R.; Rayner, Keith (a). "Orthographic and development of visual word recognition". Vision Word Recognition. Vol. II, Meaning and Context, Individuals and Development. Nova York: Psychology Press. (2012): 73-99.

Schotter, Elizabeth R.; Rayner, Keith (b). "The work of the Eyes During Reading”. The Oxford Handbook of Reading, Pollatsek, Alexander e Rebecca Treiman. (Eds.). Oxford, Nova York: Oxford University Press. 2015, pp. 44-59.

Schotter, Elizabeth R.; et al. "Parafoveal Processing in reading". Attention, Perception and Psychophysics. 74, (2012): 5-35. 
Scliar-Cabral, Leonor. "Inter-relação entre o Biológico e o Cultural: Psicolinguística e educação". Psicolinguística e Educação, Maia, Marcus. (Ed.). Campinas, São Paulo: Mercado de Letras. 2018, pp. 25-56.

Staub, Adrian; Rayner, Keith. "Eye movements and online comprehension processes". The Oxford handbook of Psycholinguistics, Gaskell, M. Gareth. (Ed.). 1a. ed. 2007, pp. 327-342.

Taylor, Jessica Nelson; Perfetti, Charles A. "Eye movements reveal readers' lexical quality and reading experience". Read and Writ. 29, (2016): 1069-1103.

Van Orden, Guy C.; Kloos, Heidi. "The Question of Phonology and Reading". Blackwell handbooks of developmental psychology. The science of reading: A handbook, Snowling, Margareth J. e Charles Hulmes. (Eds.). Amsterdam: Blackwell Publishing. 2005, pp. 61-119.

Yap. Melvin J.; Balota, David A. "Visual Word Recognition". The Oxford Handbook of Reading, Pollatsek, Alexander e Rebecca Treiman. (Eds.). Oxford, Nova York: Oxford University Press. 2015, pp. 26-43.

Recebido em: $15 / 09 / 2020$

Aceito em: 28/10/2020

Publicado em dezembro de 2020

Maria Cristina Micelli Fonseca. E-mail: mcrismfon@gmail.com. ORCID: https://orcid.org/0000-0002-0092-2895

Cad. Trad., Florianópolis, v. 40, $\mathrm{n}^{0}$ esp. 2, p. 125-148, set-dez, 2020.148 